\title{
Trabzon (KD Türkiye) Akarsu Havzalarının Coğrafi Bilgi Sistemi Kullanılarak Morfometrik Analiz Yoluyla Hidrolojik Değerlendirmesi
}

\author{
Ümit YILDIRIM ${ }^{1 *}$ \\ ${ }^{1}$ Bayburt Üniversitesi, Sanat ve Tasarım Fakültesi, İç Mimarlık ve Çevre Tasarımı Bölümü,69100, Bayburt
}

\section{Öz}

Bu çalışmada, Doğu Karadeniz Bölgesinde bulunan ve Trabzon ili sınırları içerisinden Karadeniz’e dökülen 10 farklı akarsuyun (Ağasar, Fol, Galanima, Değirmendere, Yomra, Yanbolu, Karadere, Küçükdere, Manahoz ve Solaklı dereleri) su toplama havzalarının hidrolojik açıdan incelenmesi amacıyla Coğrafi Bilgi Sistemi kullanılarak morfometrik analizleri yapılmıştır. Analizlerin yapılmasında hidrolojik süreçler ile ilgili olan morfometrik parametreler (drenaj yoğunluğu, akarsu sıklığı, drenaj dokusu, yüzeysel akış uzunluğu, şekil faktörü ve uzama oranı) kullanılmıştır. Bu parametrelerin türetilmesi için temel parametreler olarak; havza alanı, havza çevresi uzunluğu, havza uzunluğu, akış dizilimi, akış numarası ve toplam akış uzunluğu parametreleri kullanılmıştır. Yapılan morfometrik analizler sonucunda, çalışma alanında bulunan akarsu havzalarından Değirmendere, Karadere ve Solaklı havzalarının sel ve taşkın açısından daha hassas, Fol ve Ağasar havzalarında yüzey geçirimliliğinin çok düşük, Yanbolu havzasında ise toprak aşınımı ve taşınmasının oldukça yüksek olduğu belirlenmiştir.

Anahtar Kelimeler: Trabzon, akarsu havzası, morfometrik analiz, coğrafi bilgi sistemi.

\section{Hydrologic Assessment of Trabzon (NE Turkey) River Basins through the Morphometric Analysis Using Geographic Information System}

\begin{abstract}
In this study, morphometric analyses of water catchment basins of 10 different rivers (A ğasar, Fol, Galanima, Değirmendere, Yomra, Yanbolu, Karadere, Küçükdere, Manahoz and Solaklı rivers), which are located in the Eastern Black Sea Region and flows into the Black Sea within the Trabzon city, were done due to investigate the aspect of hydrology. Morphometric parameters related to hydrological processes (drainage density, stream frequency, drainage texture, length of the overland flow, form factor and elongation ratio) were used in the analysis. As the basic parameters for derivation of these parameters; basin area, basin perimeter length, basin length, stream order, stream number and total stream length parameters were used. As a result of the morphometric analysis, it was determined that Değirmendere, Karadere and Solaklı basins are more sensitive to flooding and flashflood, the surface permeability is very low in the Fol and Ağasar basins, and the soil erosion and sediment transport is quite high in the Yanbolu basin.
\end{abstract}

Keywords: Trabzon, river basin, morphometric analysis, geographic information system. 


\section{Giriş}

Giderek artan nüfusa paralel olarak artış gösteren ihtiyaçlar doğrultusunda toprak ve su kaynakları üzerindeki baskılar da artmaya başlamıştır. Bununla birlikte değişen iklim koşulları da su ve toprak yönetimi üzerinde büyük baskılar oluşturmaktadır (Yıldırım vd., 2021). Doğu Karadeniz Bölgesinde yapılan iklim projeksiyonlarında 2100 yılına kadar sıcaklıkların ve pik yağışların giderek artacağı, bu durumun da bölgede taşkın ve sel olaylarının artmasına neden olacağı öngörülmektedir (SYGM, 2016). Yapılan projeksiyonlar bölgede toplam su ihtiyacının artacağı, buna karşın su kaynakları potansiyelinin ise azalacağını göstermektedir (SYGM, 2016). Su kaynaklarının yönetiminde en temel birim akarsu havzalarıdır. Bir akarsu havzasında su kaynaklarının yönetiminde en önemli sistematik araç ise hidrolojik parametrelerdir (Rai vd., 2018). Coğrafi Bilgi Sistemi kullanılarak yapılan morfometrik analizler ile havza tabanlı hidrolojik parametrelerin değerlendirilmesi, geleneksel yöntemlere göre çok daha hızlı ve daha kolay yapılabilmektedir. Bu yöntem son yıllarda dünya çapında sıkça kullanılmaya başlanmıştır (Altaf vd., 2013; Chakrabortty vd., 2018; Kabite ve Gessesse, 2018; Mahala, 2020). Literatürde morfometrik analiz için hidrolojik, tektonik ve fizyografik değerlendirmelerin yapılmasına yardımcı olan bir çok farklı morfometrik parametre kullanılmıştır (Sreedevi vd., 2004; Ehsani ve Quiel, 2008; Taha vd., 2017; Görür ve Karadeniz, 2018; Avcı ve Sunkar, 2018; Mangan vd., 2019). Akarsu havzalarında su ve toprak kaynaklarının değerlendirilmesinde, hidrolojik süreçlerin tahmin edilmesine yardımcı olan morfometrik parametreler kullanılmaktadır. Bu parametrelerden en yaygın kullanılanları; drenaj yoğunluğu, akarsu sıklığı, drenaj dokusu, yüzeysel akış uzunluğu, şekil faktörü ve uzama oranı parametreleridir (Abboud ve Nofal, 2017; Nageswara, 2020).

Trabzon ili, değişen iklim ve antropojenik baskılar altında hidrolojik açıdan giderek hassaslaşmaya başlayan bir bölgede yer almaktadır. Bölgede neredeyse yılın her dönemi meydana gelen yağışlar ve pik yağışlarının sıklaşması bölgenin hidrolojik yönetimine daha büyük önem yüklemektedir. Bu anlamda, bu çalışmada Trabzon ilinde su ve toprak yönetimine yardımcı olmak amacıyla Coğrafi Bilgi Sistemi kullanılarak 10 farklı akarsu havzasının morfometrik analizleri yapılmış ve elde edilen sonuçlar havza yönetimi açısından değerlendirilmiştir.

\section{1. Çalışma Alanının Tanıtılması}

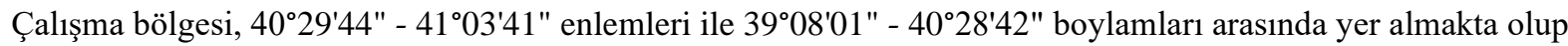
Türkiye'nin kuzey doğusunda, Doğu Karadeniz bölgesinde bulunan ve Trabzon il sınırları içerisinden Karadeniz'e dökülen 10 farklı akarsuyun (Ağasar, Fol, Galanima, Değirmendere, Yomra, Yanbolu, Karadere, Küçükdere, Manahoz ve Solaklı dereleri) su toplama havzalarını kapsamaktadır (Şekil 1). Güney-kuzey doğrultu boyunca uzanan bu akarsu havzaları, güneyde Doğu Karadeniz Dağları ile sınırlanırken, kuzeyde Karadeniz ile sınırlanmıştır. Çalışma alanının doğusunda Rize, batısında ise Giresun illeri bulunmaktadır. Değirmendere havzası 1055,17 $\mathrm{km}^{2}$ 'lik yüzey alanı ile çalışma alanının en büyük akarsu havzası iken diğer havzaların kapladıkları alanlar büyükten küçüğe doğru sırasıyla: Solaklı $\left(750,49 \mathrm{~km}^{2}\right)$, Karadere $\left(706,79 \mathrm{~km}^{2}\right)$, Yanbolu (276,65 km²), Galanima (275,29 km²), Manahoz (228,77 km²), Fol (193,76 km²), Ağasar $\left(130,74 \mathrm{~km}^{2}\right)$, Küçükdere $\left(112,50 \mathrm{~km}^{2}\right)$ ve Yomra $\left(105,91 \mathrm{~km}^{2}\right)$ havzalarıdır (Tablo 1).

Tablo 1. Çalışma alanında yer alan akarsu havzalarının alan, yükseklik ve eğim değerleri.

\begin{tabular}{llllll}
\hline \multirow{2}{*}{ Havza adı } & \multirow{2}{*}{ Kapladı̆̆ı alan $\left(\mathbf{k m}^{2}\right)$} & \multicolumn{2}{c}{ Yükseklik (m) } & \multicolumn{2}{c}{ Ĕğim (derece) } \\
& & En yüksek & Ortalama & En yüksek & Ortalama \\
\hline Ăgasar & 130,74 & 2110 & 861 & 65 & 25 \\
Fol & 193,76 & 2330 & 1142 & 76 & 22 \\
Galanima & 275,29 & 2340 & 1031 & 69 & 23 \\
Değirmendere & 1055,17 & 3080 & 1541 & 74 & 24 \\
Yomra & 105,91 & 2130 & 953 & 63 & 29 \\
Yanbolu & 276,65 & 3058 & 1479 & 72 & 25 \\
Karadere & 706,79 & 2870 & 1678 & 75 & 24 \\
Küçükdere & 112,50 & 2740 & 1084 & 63 & 22 \\
Manahoz & 228,77 & 2740 & 1293 & 69 & 23 \\
Solaklı & 750,49 & 3380 & 1578 & 74 & 25 \\
\hline
\end{tabular}

Çalışma alanında yükseklikler deniz seviyesinden başlamakta ve 3380 metreye (Solaklı havzası) kadar çıkmaktadır (Tablo 1, Şekil 2a). Ortalama yükseklikler ise 861 metre (Ağasar havzası) ile 1678 metre (Karadere havzası) arasında değişmektedir (Tablo 1). Havzalarda eğimler $0^{\circ}$ ile $76^{\circ}$ arasında (Tablo 1) değişmekte olup yüksekliklerin 3000 metreden daha fazla olduğu alanlarda eğimler düşüktür (Şekil 2b). Yükseklik ve eğimlerin 
havzalara göre dağılımı Tablo 1'de gösterilmiştir.

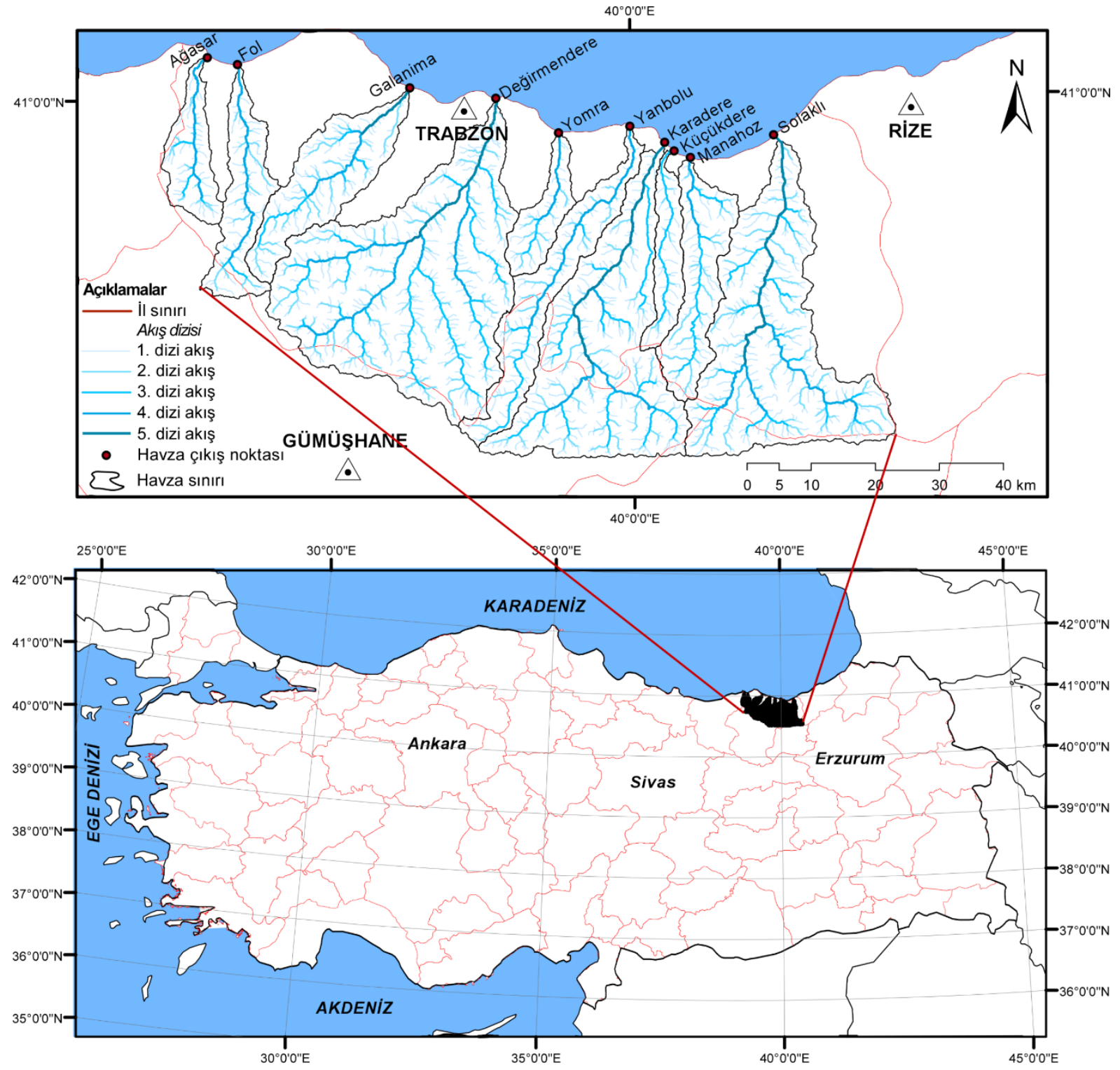

Şekil 1. Çalışma alanının yer bulduru haritası.

Çalışma alanında kışlar 11 k, yazlar ise nispeten sıcak geçmekte olup yağışlar neredeyse yılın her döneminde görülmektedir (Akkaş, 1990). Dağların denize paralel olarak uzandığı bölgede, yağışlar, deniz kaynaklı oluşan nemli havanın dağlarda oluşturduğu orografik yağışlardır. 1927-2019 yılları arasında Meteoroloji Genel Müdürlüğü'nün yapmış olduğu ölçümlere göre, Trabzon ili için yıllık ortalama yağış miktarı 829,6 mm, yıllık ortalama sıcaklık değeri ise $14,7^{\circ} \mathrm{C}^{\prime}$ dir (MGM, 2021). Çalışma alanında, deniz seviyesinden 2300 metre yüksekliklere kadar çoğunlukla sık ormanlık alanlar bulunmaktadır. Kıyı şeridinde daha çok taflani, findık, kızılcık, muşmula, defne ve ormangülü gibi türler yaygın iken, 300-350 metre yüksekliklere kadar kızılağaç, kayıs1, meşe ve kestane ağaçlarından oluşan ormanlar, 600-800 metre yüksekliklerde meşe ve gürgen ormanları, 1200 metre yüksekliklere kadar olan alanlarda kestane, meşe, şimşir, kızılağaç ve ıhlamur ağaçlarından oluşan ormanlar, 1200-1600 metre yükseklikler arasında karışık ormanlar, 1600 metreden 2300 metre yüksekliğindeki alanlarda çam, ladin ve köknar ağaçlarından oluşan ormanlar, bu yükseltiden sonra ise çayır ve dağ otlakları bulunmaktadır (Akkaş, 1990). 

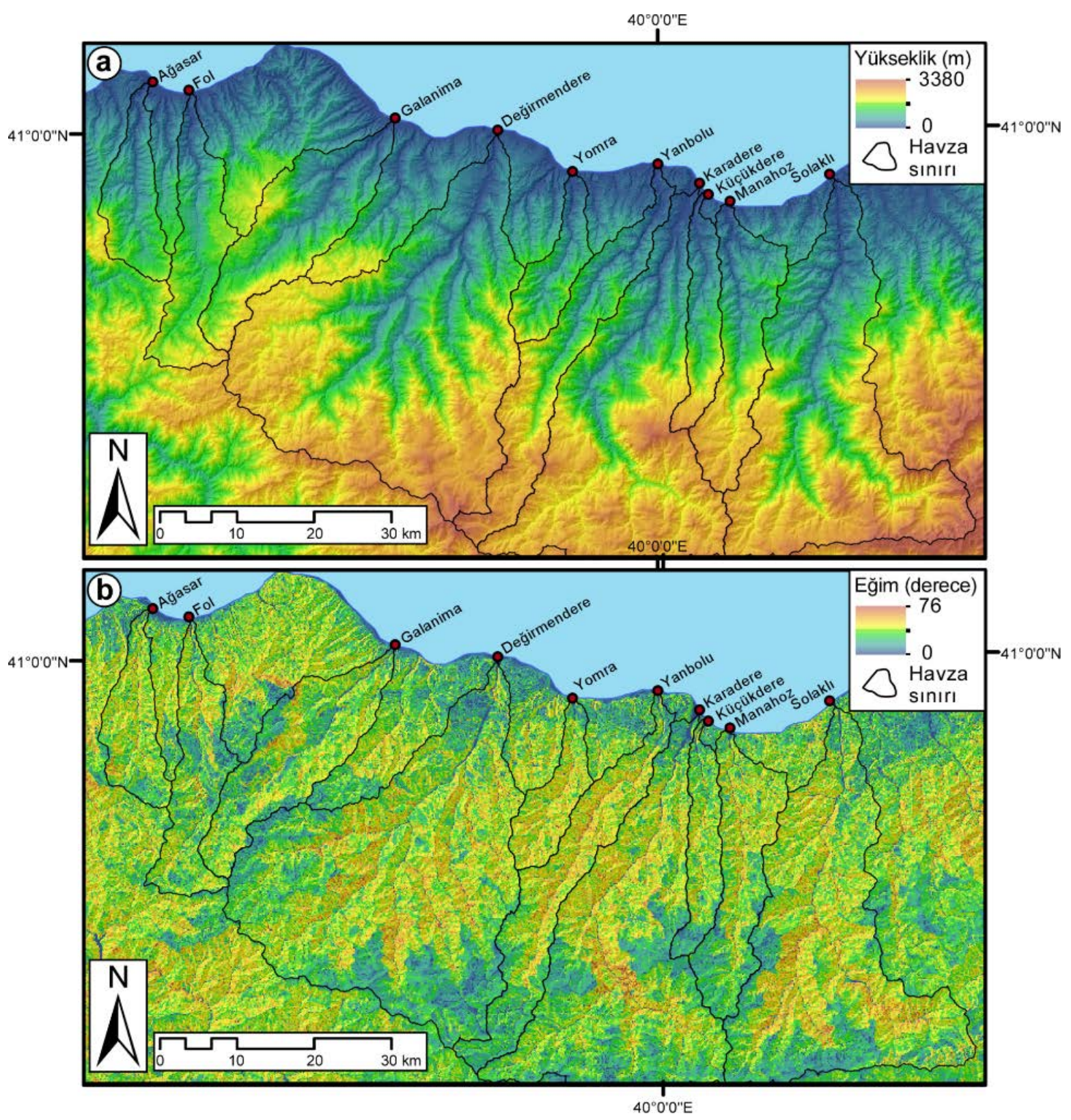

Şekil 2. Çalışma alanının sayısal yükseklik modeli (a) ve eğim haritası (b).

Çalışma alanı Doğu Pontid dağ kuşağı üzerinde yer almakta olup bölgede yaşlıdan gence doğru; Alt Jura-Üst Kretase yaşlı volkano-tortullar ve Üst Jura-Alt Kretase yaşlı neritik kireçtaşları, Üst Kretase yaşlı dasit, riyolit, riyodasit, Üst Kretase-Paleosen yaşlı kırıntılı ve karbonat kayaçlar, Paleosen-Eosen yaşlı granitoid, diyorit, kuvars diyorit, tonalit, Eosen yaşlı volkanitler ve Pliyo-Kuvaterner yaşlı kırıntılılar ile alüvyonlar bulunmaktadır (MTA, 2002) (SSekil 3). Birimler arasında geçişler, bazı bölgelerde uyumlu iken bazı bölgelerde ya KD-GB doğrultulu faylar (Şekil 3) ile ya da farklı karakterlerdeki uyumsuzluklar ile karakteristiktir. Çalışma alanında yüzeyleyen en yaygın jeolojik birim, alanın yaklaşık \%50'sini kaplayan volkano-tortullardır (Şekil 3). Volkanitler özellikle çalışma alanının kuzey batı kesiminde, çoğunlukla Ağasar ve Fol havzalarında görülürken, çalışma alanın orta kesimlerinde volkanitler ile volkano-tortullar arasında kırıntılı karbonatlar yer almaktadır. Alanın güneydoğu kesimlerinde ise daha çok Solaklı havzasında yüzlekler vermiş granitoidler yaygındır. Çalışma alanının kıyı kesimlerinde, Neojen yaşlı volkanitlerin üzerine uyumsuzlukla yerleşmiş Pliyo-Kuvaterner yaşlı kırıntılılar yüzeylenmektedir (Aydın vd., 2008). 


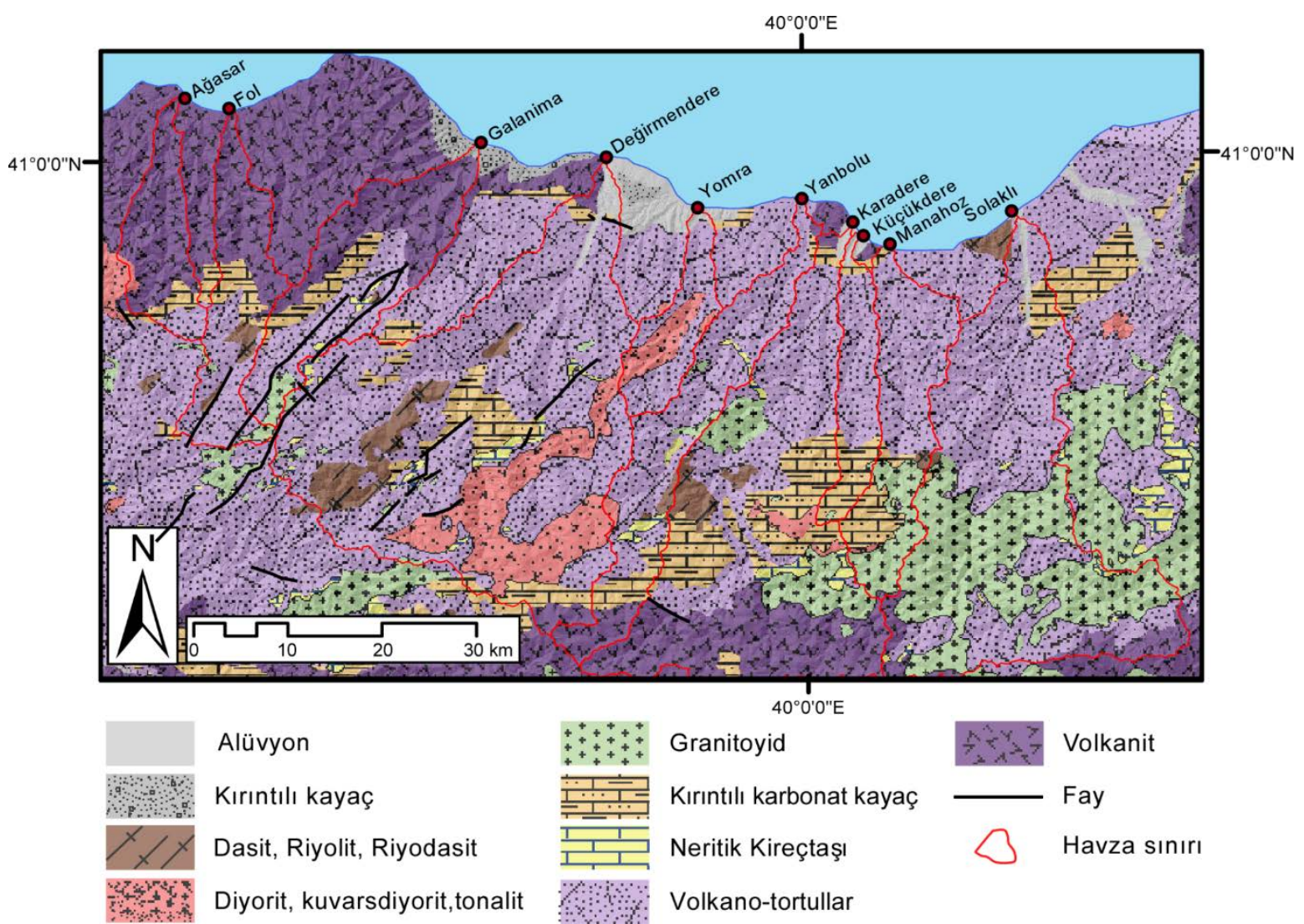

Şekil 3. Çalışma alanı ve civarının jeoloji haritası (MTA, 2002'den değiştirilerek).

\section{Materyal ve Metot}

\subsection{Materyal}

Havza morfometrisi analizlerinin en temel verisi Sayısal Yükseklik Modeli (SYM)'dir (Waikar ve Nilawar, 2014; Taha vd., 2017; İmamoğlu, 2020). Çalışma alanına ait sayısal yükseklik modelinin oluşturulmasında Harita Genel Komutanlığı'nın yayınlamış olduğu 1/50.000 ölçekli (F42c,d; F43c,d; G42a,b,c,d; G43a,b,c,d; G44a,b,c,d paftaları) topoğrafik haritaları kullanılmıştır. Çalışma kapsamında, morfometrik analizler için gerekli verilerin üretilmesinde bir coğrafi bilgi sistemi yazılımı olan ArcGIS 10.3. programı ve ilgili eklentiler kullanılmıştır.

\subsection{Metot}

Morfometrik analizin temel verisi olan sayısal yükseklik modelinin üretilmesinde, ilk olarak bölgeyi temsil eden topoğrafik haritalar tarayıcı yardımıyla dijital ortama aktarılmıştır. Sonrasında, ArcGIS ortamında bu dijital görüntü, jeoreferanslama aracı kullanılarak koordinatlandırılmış̧ır. Koordinat sistemi olarak Universal Transverse Mercator (UTM), World Geodetic System (WGS 1984), Zone 37N kullanılmıştır. Koordinatlandırılmış görüntü üzerinde, yine ArcGIS ortamında manuel dijitalleştirme yöntemi kullanılarak çalışma alanının bütün eş yükselti eğrileri dijitalleştirilmiş ve her bir eğriye ait yükseklik değerleri öznitelik verisi olarak tanıtılmıştır. Sayısallaştırılmış bu eş yükselti eğrileri kullanılarak 3D Analyst aracı içerisinde yer alan "topo to raster” eklentisi ile sayısal yükseklik modeli (SYM)'ne dönüştürülmüştür.

Çalışma alanının sayısal yükseklik modeli ile ArcGIS içerisinde bulunan ArcHYDRO aracı ile sırasıyla, fill DEM, flow direction, flow accumulation, stream order, stream to feature ve watershed eklentileri kullanılarak havza sınırları ve havzalardaki akarsu ağları oluşturulmuştur. Akarsu dizilimi oluşturulurken Strahler dizilimi (Strahler, 1964) kullanılmıştır.

Bu çalışmada kullanılan morfometrik parametreler, "Temel parametreler" ve bu parametrelerden türetilmiş "Karakteristik parametreler" olarak iki farklı gruba ayrılmışırı (Tablo 2). Akarsu havzalarının birbirleriyle karşılaştırılması ve hidrolojik yanıtlarının değerlendirilmesinde karakteristik parametreler kullanılmaktadır. 
Temel parametreler daha çok fiziksel özellikleri yansıtmaktadır. Çalışma kapsamında kullanılan morfometrik parametreler ve bu parametrelerin oluşturulmasında kullanılan formüller ve detaylı açıklamaları Tablo 2'de gösterilmiştir.

Temel parametrelerden, havza alanı (A), havza çevresi uzunluğu (P), akış numarası $\left(\mathrm{N}_{\mathrm{u}}\right)$, toplam akış uzunluğu $\left(\mathrm{L}_{\mathrm{u}}\right)$ ve ortalama akış uzunluğu $\left(\mathrm{L}_{\mathrm{sm}}\right)$ parametrelerinin hesaplanması ArcGIS içerisinde öznitelik verisi hesaplamaları kullanılarak yapılmıştır.

Tablo 2. Morfometrik analizlerde kullanılan parametreler ile bu parametrelerin formülleri.

\begin{tabular}{|c|c|c|}
\hline \multicolumn{3}{|c|}{ Temel Parametreler } \\
\hline Morfometrik parametre & Yöntem, Formül ve Birim & Kaynak \\
\hline Havza alanı (A) & Havzanın kapladığı alan $\left(\mathrm{km}^{2}\right)$ & Arc ölçüm eklentisi \\
\hline Havza çevresi uzunluğu (P) & Havza sınır çizgisinin uzunluğu $(\mathrm{km})$ & Schumm, 1956 \\
\hline Havza uzunluğu $(\mathrm{L} b)$ & $\begin{array}{l}\text { Ana akarsu koluna paralel çizilen çizginin uzunluğu } \\
(\mathrm{km})\end{array}$ & Schumm, 1956 \\
\hline Akış dizilimi (U) & Hiyerarşik sıra & Strahler, 1964 \\
\hline Akıs numarasi $\left(\mathrm{N}_{\mathrm{u}}\right)$ & Akarsu kollarının sayısı & Horton, 1945 \\
\hline Toplam akış uzunluğu $\left(\mathrm{L}_{\mathrm{u}}\right)$ & Havzadaki akarsu kollarının toplam uzunluğu (km) & Horton, 1945 \\
\hline Ortalama akış uzunluğu $\left(\mathrm{L}_{\mathrm{sm}}\right)$ & $\mathrm{Lu} / \mathrm{N}_{\mathrm{u}}(\mathrm{km})$ & Strahler, 1964 \\
\hline \multicolumn{3}{|c|}{ Temel Parametreler } \\
\hline Morfometrik parametre & Yöntem, Formül ve Birim & Kaynak \\
\hline Drenaj yoğunluğu $\left(\mathrm{D}_{\mathrm{d}}\right)$ & $\mathrm{Lu} / \mathrm{A}$ & Horton, 1932 \\
\hline Akarsu siklığ $\left(\mathrm{F}_{\mathrm{s}}\right)$ & $\mathrm{N}_{\mathrm{u}} / \mathrm{A}$ & Horton, 1945 \\
\hline Drenaj dokusu $\left(\mathrm{D}_{\mathrm{t}}\right)$ & $\mathrm{Nu}_{\mathrm{u}} / \mathrm{P}$ & Horton, 1945 \\
\hline Yüzeysel akış uzunluğu $\left(\mathrm{Lg}_{\mathrm{g}}\right)$ & $1 / 2 \mathrm{D}_{\mathrm{d}}$ & Horton, 1945 \\
\hline Şekil faktörü $\left(\mathrm{R}_{\mathrm{f}}\right)$ & $\mathrm{A} / \mathrm{Lb}^{2}$ & Horton, 1932 \\
\hline Uzama oranı $\left(\mathrm{R}_{\mathrm{e}}\right)$ & $\frac{2 \sqrt{\frac{A}{\pi}}}{L_{h}}$ & Schumm, 1956 \\
\hline
\end{tabular}

\section{Bulgular ve Tartışma}

\subsection{Temel Parametreler}

Akarsu havzalarının karakteristik özelliklerini yansıtan karakteristik morfometrik parametrelerin türetilmesinde kullanılan temel morfometrik parametreler, akarsu havzalarının hidrolojik değerlendirmelerinde tek başına doğrudan bir yargı çıkaramasa da havzaların karşılaştırılmasında oldukça önemlidirler (Mosaad, 2017; Kabite ve Gessesse, 2018). Çalışma alanında bulunan akarsu havzalarının temel morfometrik parametre değerleri Tablo 3'de verilmiştir. Bölgedeki havzaların kapsadıkları alanlar (A) 105,91 km² ile 1055,17 km² arasında değişmekte olup en küçük havza Yomra havzası, en büyük havza ise Değirmendere havzasıdır (Tablo 3). Havza çevresi uzunluğu (P), havzadaki akış kanalları ile birlikte değerlendirildiğinde, havzanın yüzey akışını kontrol eden süreçlerin değerlendirilmesine yardımcı olan önemli bir morfometrik parametredir (Horton, 1945). Çalışma alanında, Değirmendere havzası 180,14 km ile en uzun havza sınırı uzunluğuna sahip havza iken Yomra havzası en kısa havza sınırı uzunluğuna sahip havzadır (Tablo 3). Havza uzunluğu ( $\mathrm{L}_{b}$ ) parametresi, havzanın başlangıç noktası ile çıkış noktası arasında kalan ve ana akarsuya paralel çizilen çizginin uzunluğunu ifade etmektedir (Schumm, 1956). Havza uzunluğu, havzaların şekilsel olarak ifadesine yardımcı olurken, havzalarda yüzey akışının hızının tahmininde kullanılan temel girdi parametrelerindendir. Çalışma alanında yer alan havzaların havza uzunluğu $\left(\mathrm{L}_{\mathrm{b}}\right)$ değerleri 27,47 km ile 70,10 km arasında değişmek olup en düşük değer Yomra havzasına, en yüksek değer ise Karadere havzasına aittir (Tablo 3). Akış dizilimi (U), yüzeysel akışı oluşturan akış kanallarının hiyerarşik olarak sıralamasını ifade etmektedir ve akarsu havzalarının fizyografik ve tektonik değerlendirmesinde kullanılan önemli parametrelerden bir tanesidir (Iqbal vd., 2013; Harsha vd., 2020). Çalışma alanında bulunan Karadere havzasında en fazla 3. dizi akış gözlenirken, Ağasar, Fol, Yomra, Yanbolu ve Manahoz havzalarında 4. dizi akış, Galanima, Değirmendere, Karadere ve Solaklı havzalarında ise en fazla 5. dizi akış görülmektedir. Akış numarası $\left(\mathrm{N}_{\mathrm{u}}\right)$, akış kollarının sayısını ifade etmektedir (Horton, 1945). Akış numarası $\left(\mathrm{N}_{\mathrm{u}}\right)$ parametresi, akarsu havzalarında yüzey akışının tahmininde kullanılan temel parametrelerden bir tanesidir (Aparna vd., 2015). Çalışma alanında bulunan akarsu havzalarının akış numaraları 56 (Küçükdere havzası) ile 579 (Değirmendere havzası) arasında değişmektedir (Tablo 3). Akış kollarının uzunluğu ise akış uzunluğu $\left(\mathrm{L}_{\mathrm{u}}\right)$ parametresini ifade etmekte olup havzalarda yüzeysel akışın değerlendirmesinde temel parametre olarak kullanılmaktadır (Horton, 1945). Akış uzunluğu daha düşük olan havzalarda yüzey geçirimliliği daha fazla, 
akış uzunluğunun daha fazla olduğu havzalarda ise yüzey geçirimliliği daha düşüktür (Nageswara, 2020). Ortalama akış uzunluğu $\left(\mathrm{L}_{\mathrm{sm}}\right)$ bu karşılaştırmaların yapılabilmesi için yardımcı olabilecek bir morfometrik parametredir. Çalışma alanında bulunan havzalar içerisinde en düşük akarsu uzunluğu değeri 93,68 km ile Karadere havzasına ait iken Değirmendere havzası 938,19 km ile en yüksek akarsu uzunluğu değerine sahiptir (Tablo 3). Ortalama akış uzunluğunun $\left(\mathrm{L}_{s m}\right)$ en düşük olduğu havza Yanbolu havzası $(0,86 \mathrm{~km})$ iken 1,67 km ile Küçükdere havzası ortalama akış uzunluğunun en yüksek olduğu havzadır (Tablo 3).

Tablo 3. Çalışma alanında bulunan havzaların temel morfometrik parametre değerleri.

\begin{tabular}{|c|c|c|c|c|c|c|c|}
\hline \multicolumn{8}{|c|}{ Temel Parametreler } \\
\hline Havza adı & A & $\mathbf{P}$ & $\mathbf{L}_{\mathbf{b}}$ & $\mathbf{U}$ & $\mathbf{N}_{\mathbf{u}}$ & $\mathbf{L}_{\mathbf{u}}$ & $\mathbf{L}_{\mathrm{sm}}$ \\
\hline Ağasar & 130,74 & 69,03 & 31,87 & 4 & 81 & 128,26 & 1,58 \\
\hline Fol & 193,76 & 102,88 & 45,87 & 4 & 118 & 170,45 & 1,44 \\
\hline Galanima & 275,29 & 99,91 & 47,47 & 5 & 157 & 260,76 & 1,66 \\
\hline Değirmendere & 1055,17 & 180,14 & 65,71 & 5 & 579 & 938,19 & 1,62 \\
\hline Yomra & 105,91 & 60,55 & 27,47 & 4 & 65 & 95,05 & 1,46 \\
\hline Yanbolu & 276,65 & 147,49 & 69,08 & 4 & 162 & 139,26 & 0,86 \\
\hline Karadere & 706,79 & 168,73 & 70,10 & 5 & 379 & 617,89 & 1,63 \\
\hline Küçükdere & 112,50 & 76,83 & 37,53 & 3 & 56 & 93,68 & 1,67 \\
\hline Manahoz & 228,77 & 102,23 & 45,40 & 4 & 121 & 200,21 & 1,65 \\
\hline Solaklı & 750,49 & 174,69 & 69,58 & 5 & 434 & 674,10 & 1,55 \\
\hline
\end{tabular}

\subsection{Karakteristik Parametreler}

Karakteristik parametreler, akarsu havzalarının hidrolojik, fizyografik ve tektonik karakteristiklerinin değerlendirilmesinde kullanılan parametrelerdir. Çalışma alanında bulunan akarsu havzalarının karakteristik morfometrik parametre değerleri aşağıda Tablo 4'de verilmiştir.

Drenaj yoğunluğu $\left(D_{d}\right)$, akarsu sıklığı $\left(F_{s}\right)$, drenaj dokusu $\left(D_{t}\right)$ ve yüzeysel akış uzunluğu $\left(L_{g}\right)$ parametreleri, akarsu havzalarında yüzeysel akış ile ilgili hidrolojik süreçlerinin değerlendirilmesinde kullanılan önemli parametrelerdir (Joji vd., 2013; Pophare ve Balpande, 2014; Kabite ve Gessesse, 2018). Drenaj yoğunluğu ( $\left.D_{d}\right)$, birim alandaki akarsu kollarının uzunluğunun oranıdır (Horton, 1932). Drenaj yoğunluğu, havzanın iklimi ve bitki örtüsü, havzada yüzeylenen kayaçların ve toprakların özellikleri ve arazi şekilleri (tepeler, vadiler, platolar vb. gibi) ile yakından ilişkilidir (Carlston, 1966; Rodriguez-Iturbe ve Escobar, 1982). Yüksek drenaj yoğunluğuna sahip havzalarda, yüzey geçirimliliği daha düşük olup bu havzalarda yüzeysel akış miktarı daha fazladır (Rai vd., 2017). Çalışma alanında en düşük drenaj yoğunluğuna sahip havza $0,50 \mathrm{~km} / \mathrm{km}^{2}$ ile Yanbolu havzası iken, Ağasar havzası $0,98 \mathrm{~km} / \mathrm{km}^{2}$ ile en yüksek drenaj yoğunluğuna sahip havzadır (Tablo 4). Yanbolu havzasında ortalama akış uzunluğunun da en düşük $\left(\mathrm{L}_{\mathrm{sm}}=0,86 \mathrm{~km}\right.$ ) olduğu görülmektedir. Bu durum Yanbolu havzasında yüzey geçirimliliğinin diğer havzalara göre daha fazla olduğunu göstermektedir.

Akarsu sıklığ $1\left(F_{s}\right)$, birim alandaki akarsu kollarının sayısının oranıdır (Horton, 1945). Akarsu sıklığı parametresi, havzada yüzeylenen kayaçların geçirimliliği ile yakından ilişkili bir parametre olup bu durum havzada yüzey akışını etkilemektedir (Abboud ve Nofal, 2017). Geçirimliliği düşük olan birimlerin yoğun olduğu havzalarda akarsu sıklığ ${ }\left(F_{s}\right)$ değeri yüksektir (Abboud ve Nofal, 2017). Çalışma alanında bulunan akarsuların akarsu sıklığ1 $\left(F_{s}\right)$ değerleri 0,498 (Küçükdere havzası) ile 0,620 (Ağasar havzası) arasında değişmektedir (Tablo 4). Ağasar, Fol ve Yomra havzalarının akarsu sıklığı değerleri yüksek olup bu havzalarda yüzey geçirimliliği daha düşüktür. $\mathrm{Bu}$ durum yüzeysel akışın bu havzalarda daha fazla olabileceğini göstermektedir. Bu havzalarda yüzeylenen litolojik birimlere bakıldığında, volkanit, dasit, kuvarsdiyorit, tonalit birimlerinin yaygın olduğu görülmektedir (Şekil 3). Bu birimlerin gözenekliliği ve geçirimliliği oldukça düşüktür.

Drenaj dokusu $\left(D_{t}\right)$, havza sınır çizgisi uzunluğu ile havzadaki akarsuların toplam uzunluğunun oranlamasının bir ifadesidir (Horton, 1945). Smith (1950), havzaları drenaj dokusu değerlerine: çok ince $\left(D_{t}>8\right)$, ince $\left(D_{t}=6-8\right)$, orta $\left(D_{t}=4-6\right)$, kaba $\left(D_{t}=2-4\right)$, çok kaba $\left(D_{t}<2\right)$ olacak şekilde 5 sınıfa ayırmıştır. Havzalarda drenaj dokusunu belirleyen en temel faktör, zeminin sızma kapasitesidir. Bununla birlikte, topoğrafya, iklim, bitki örtüsü ve tektonizma da drenaj dokusunu etkileyen faktörlerdendir (Magesh ve Chandrasekar, 2014; Rai vd., 2018). Çalışma alanında, en düşük drenaj dokusu $\left(\mathrm{D}_{\mathrm{t}}\right)$ değeri 0,73 ile Küçükdere havzasına ait iken, Değirmendere havzası 3,21 ile en yüksek drenaj dokusu değerine sahiptir (Tablo 4). Çalışma alanında Değirmendere, Solaklı ve Karadere havzaları "kaba" drenaj dokusu grubunda iken diğer havzalar "çok kaba" drenaj dokusu grubundadır.

Yüzeysel akış uzunluğu $\left(\mathrm{L}_{\mathrm{g}}\right)$, yeryüzüne düşen yağışın, yüzeyde en yakın akarsu kanalına ulaşma mesafesi ile alakalı olan ve havzalarda toprak erozyonu, taşınması ve taşınan malzemelerin birikimi gibi süreçlerin tahmininde 
kullanılan oldukça önemli bir parametredir (Horton, 1945). Havzalardaki yüksek yüzeysel akış uzunluğu değerleri, bu havzalarda seyelan şeklinde oluşacak yüzey akışının daha fazla olacağını göstermektedir (Elbaşı ve Özdemir, 2018). Yanbolu havzası, 0,99 ile en yüksek yüzeysel akış uzunluğu ( $\mathrm{L}_{\mathrm{g}}$ ) değerine sahip havzası olup bu havzada akış kaynaklı toprak aşınımı ve taşınması diğer havzalara göre daha yüksektir.

Şekil faktörü $\left(R_{f}\right)$ ve uzama oranı $\left(R_{e}\right)$ parametreleri, havzaların şekilsel özelliklerini kullanarak hidro-fizyografik değerlendirmelerin yapılmasına yardımcı olan parametrelerdir. Şekil faktörü $\left(R_{f}\right)$, akarsu havzalarında havza alanının maksimum havza uzunluğunun karesine oranı (Horton, 1932) olup havzalarda yüzeye düşen akışın havza çıkışına varma süresi ile havzada oluşabilecek taşkın gibi hidrolojik olguların tahmininde kullanılan oldukça önemli bir parametredir (Özhan, 2004). Yüksek şekil faktörü $\left(\mathrm{R}_{\mathrm{f}}\right)$ değerine sahip havzalar, dar ve uzun şekillerde iken düşük şekil faktörü $\left(R_{f}\right)$ değerine sahip havzaların şekilleri daha yuvarlaktır (Horton, 1932). Dairesel havzalarda akışın bir kanalda toplanma oranı daha yüksek olacak ve bu durum bu havzalarda kısa süreli yüksek pik akışlarını oluşturacaktır (Horton, 1932; Rai vd., 2017). Çalışma alanındaki havzaların şekil faktörü değerleri 0,06 ile 0,24 arasında değișmekte olup en düșük şekil faktörü değeri Yanbolu havzasına, en yüksek akıș faktörü değeri ise Değirmendere havzasına aittir (Tablo 4). Akarsu havzalarında uzama oranı ( $\mathrm{R}_{\mathrm{e}}$ ) parametresi, havzaların yuvarlaklık ya da uzamış şeklini ifade eden bir parametredir. Uzama oranı $\left(\mathrm{R}_{\mathrm{e}}\right)$ değeri yüksek olan havzalar şekil olarak daha fazla dairesel şekilli olup bu havzalarda yüzey akışının boşalımı daha verimlidir (Singh ve Singh, 1997). Ayrıca bu yüksek uzama oranına sahip havzalarda, yüzeyin sızma kapasitesi de daha yüksektir ve bu havzalarda yüzey akışı daha yavaştır (Reddy vd., 2004). Bununla birlikte uzamış havzalarda aşınma, dairesel havzalara göre daha fazladır (Reddy vd., 2004). Çalışma alanında en yüksek uzama oranı ( $\left.R_{e}\right)$ 0,56 ile Değirmendere havzasına ait iken, en düşük uzama oranı değeri 0,27 ile Yanbolu havzasına aittir. Havzaların şekil faktörü $\left(R_{f}\right)$ ve uzama oranı $\left(R_{e}\right)$ değerlerine bakıldığında, Değirmendere havzasının çalışma alanında daha yuvarlağa yakın bir şekle sahip olduğu ve bu havzada kısa süreli pik akışlarının oluşma potansiyelinin diğer havzalara oranla daha yüksek olduğu ortaya çıkmaktadır. Bununla birlikte, Yanbolu havzası en fazla uzamış şekilli havza olup bu havzada yüzey akışı daha yüksek, aşınma ve sediment taşınması daha fazladır. Uzamış havzalarda sel ve taşkın olaylarının yönetimi dairesel havzalara göre daha kolaydır (Singh, 1998).

Tablo 4. Çalışma alanında bulunan havzaların karakteristik morfometrik parametre değerleri.

\begin{tabular}{|c|c|c|c|c|c|c|}
\hline \multicolumn{7}{|c|}{ Morfometrik Parametreler } \\
\hline Havza adı & $\mathbf{D}_{\mathbf{d}}$ & $\mathbf{F}_{\mathrm{s}}$ & $\mathbf{D}_{\mathrm{t}}$ & $\mathbf{L g}$ & $\mathbf{R f}_{\mathrm{f}}$ & $\mathbf{R} \mathbf{e}$ \\
\hline Ăgasar & 0,98 & 0,620 & 1,17 & 0,51 & 0,13 & 0,40 \\
\hline Fol & 0,88 & 0,609 & 1,15 & 0,57 & 0,09 & 0,34 \\
\hline Galanima & 0,95 & 0,570 & 1,57 & 0,53 & 0,12 & 0,39 \\
\hline Değirmendere & 0,89 & 0,549 & 3,21 & 0,56 & 0,24 & 0,56 \\
\hline Yomra & 0,90 & 0,614 & 1,07 & 0,56 & 0,14 & 0,42 \\
\hline Yanbolu & 0,50 & 0,586 & 1,10 & 0,99 & 0,06 & 0,27 \\
\hline Karadere & 0,87 & 0,536 & 2,25 & 0,57 & 0,14 & 0,43 \\
\hline Küçükdere & 0,83 & 0,498 & 0,73 & 0,60 & 0,08 & 0,32 \\
\hline Manahoz & 0,88 & 0,529 & 1,18 & 0,57 & 0,11 & 0,38 \\
\hline Solaklı & 0,90 & 0,578 & 2,48 & 0,56 & 0,16 & 0,44 \\
\hline
\end{tabular}

\section{Sonuç ve Öneriler}

Bu çalışmada, Trabzon ili sınırları içerisinden Karadeniz’e dökülen 10 farklı akarsuyun su toplama havzalarında hidrolojik süreçlerin değerlendirilmesi amacıyla Coğrafi Bilgi Sistemi yöntemi kullanılarak morfometrik analizler yapılmıştır. Bu kapsamda, çalışma alanına ait topoğrafik haritalar sayısallaştırılarak bölgenin sayısal yükseklik modeli oluşturulmuştur. $\mathrm{Bu}$ model temel girdi parametresi olarak kullanılmış ve temel morfometrik parametrelerin değerleri hesaplanmıştır. Sonrasında temel morfometrik parametreler kullanılarak, ilgili formüller ile karakteristik morfometrik parametrelerin değerleri elde edilmiştir.

Çalışma alanında bulunan akarsu havzaları genel olarak uzamış şekilli havzalar olup Değirmendere, Karadere ve Solaklı havzaları diğer havzalara göre daha az uzamış şekilli havzalardır. Bu havzalar taşkın ve sel potansiyeli açısından diğer havzalara göre daha hassastırlar. Fol, Yanbolu ve Küçükdere havzaları ise en fazla uzamış havzalar olup bu havzalarda sel ve taşkın gibi hidrolojik olguların yönetimi diğer havzalara göre daha kolaydır.

Ağasar ve Fol havzalarında yüzeysel geçirimlilik düşük olup bu bölgelerde yüzeysel akış daha fazladır. Bununla birlikte sızma kapasitesi açısından, Yanbolu havzası yüzeysel geçirimliliğin en fazla olduğu havzadır ve bu havzada toprak aşınımı ve taşınması süreçleri diğer havzalara göre daha yoğun bir şekilde gerçekleşmektedir. 
Karadeniz bölgesinde, değişen iklim koşulları ve kentleşmenin artması nedeniyle arazi kullanımında ortaya çıkan değişimler, bu bölgede son yıllarda sıkça sel ve taşkın felaketlerinin ortaya çıkmasına neden olmaktadır. Morfometrik analiz yoluyla havzalarda toprak ve su yönetimi daha verimli ve hızlı bir şekilde yapılmaktadır. Dolayısıyla, Trabzon ilinde havza tabanlı hidrolojik değerlendirmelerin yapılması ve havza yönetiminin planlanması açısından, yapılan bu çalışma karar vericilere önemli bir katkı sağlayacaktır.

\section{Kaynaklar}

1. Abboud, I. A., Nofal, R. A. (2017). Morphometric analysis of wadi Khumal basin, western coast of Saudi Arabia, using remote sensing and GIS techniques, Journal of African Earth Sciences, 126, 58-74.

2. Akkaş, M. (1990). Trabzon İklim Etüdü, T.C. Başbakanlık Devlet Meteoroloji İşleri Genel Müdürlüğü, Ankara, $107 \mathrm{~s}$.

3. Altaf, F., Meraj, G., Romshoo, S. A. (2013). Morphometric analysis to infer hydrological behavior of Lidder Watershed, Western Himalaya, India, Geography Journal, 2013.

4. Aparna, P., Nigee, K., Shimna, P., Drissia, T. K. (2015). Quantitative analysis of geomorphology and flow pattern analysis of Muvattupuzha River Basin using Geographic Information System, Aquatic Procedia, 4, 609-616.

5. Avcı, V., Sunkar, M. (2018). Bulancak'ta (Giresun) sel ve taşkın olaylarına neden olan Pazarsuyu, İncüvez, Kara ve Bulancak derelerinin morfometrik analizleri, Fırat Üniversitesi Sosyal Bilimler Dergisi, 28 (2), 1541.

6. Aydın, F., Karsli, O., Chen, B. (2008). Petrogenesis of the Neogene alkaline volcanics with implications for post-collisional lithospheric thinning of the Eastern Pontides, NE Turkey. Lithos, 104, 249-266.

7. Carlston, C. W. (1966). The effect of climate on drainage density and streamflow, Hydrological Sciences Journal, 11 (3), 62-69.

8. Chakrabortty, R., Ghosh, S., Pal Subodh, C., Das, B., Malik, S. (2018). Morphometric analysis for hydrological assessment using Remote Sensing and GIS technique: A case study of Dwarkeswar River Basin of Bankura District, West Bengal, Asian Journal of Research in Social Sciences and Humanities, 8 (4), 113-142.

9. Elbaşı, E., Özdemir, H. (2018). Marmara denizi akarsu havzalarının morfometrik analizi, Coğrafya Dergisi, 36, 63-84.

10. Ehsani, A. H., Quiel, F. (2008). Geomorphometric feature analysis using morphometric parameterization and artificial neural networks, Geomorphology, 99 (1), 1-12.

11. Görür, A. E., Karadeniz, C. (2018). Morfometrik parametrelerin havza hidrolojisi bakımından değerlendirilmesi, Türkiye Ormancılık Dergisi, 19 (4), 447-454.

12. Harsha, J., Ravikumar, A. S., Shivakumar, B. L. (2020). Evaluation of morphometric parameters and hypsometric curve of Arkavathy river basin using RS and GIS techniques, Applied Water Science, 10, 86.

13. Horton, R. E. (1932). Drainage basin characteristics, Transactions of the American Geophysical Union, 13, 350-361.

14. Horton, R. E. (1945). Erosional development of streams and their drainage basins: hydrophysical approach to quantitative morphology, Geological Society of America Bulletin, 56 (3), 275-370.

15. Iqbal, M., Sajjad, H., Bhat, F. A. (2013). Morphometric analysis of Shaliganga Sub Catchment, Kashmir Valley, India using Geographical Information System, International Journal of Engineering Trends and Technology, 4 (1).

16. İmamoğlu, A. (2020). Alaca Çayı Havzası erozyon durumunun morfometrik ölçümler ile ilişkisi, Avrupa Bilim ve Teknoloji Dergisi, 18, 868-878.

17. Joji, V. S., Nair, A. S. K., Baiju, K. V. (2013). Drainage basin delineation and quantitative analysis of Panamaram Watershed of Kabani River Basin, Kerala using remote sensing and GIS, Journal Geological Society of India, 82.

18. Kabite, G., Gessesse, B. (2018). Hydro-geomorphological characterization of Dhidhessa River Basin, Ethiopia, International Soil and Water Conservation Research, 6, 175-183.

19. Magesh, N. S., Chandrasekar, N. (2014). GIS model-based morphometric evaluation of Tamiraparani sub-basin, Tirunelveli district, Tamil Nadu, India. Arab J Geosci, 7, 131-141.

20. Mahala, A. (2020). The signifcance of morphometric analysis to understand the hydrological and morphological characteristics in two diferent morpho-climatic settings, Applied Water Science, 10, 33.

21. Mangan, P., Haq, M. A., Baral, P. (2019). Morphometric analysis of watershed using remote sensing and GIS - a case study of Nanganji River Basin in Tamil Nadu, India, Arabian Journal of Geosciences, 12, 202.

22. MGM (2021). https://www.mgm.gov.tr/veridegerlendirme/il-ve-ilceleristatistik.aspx?k=A\&m=TRABZON, T. C. Tarım ve Orman Bakanlığı, Meteroloji Genel Müdürlüğü, (05.01.2021). 
23. Mosaad, S. (2017). Geomorphologic and geologic overview for water resources development: Kharit basin, Eastern Desert, Egypt, Journal of African Earth Sciences, 134, 56-72.

24. MTA (Maden Tetkik ve Arama Genel Müdürlüğü) (2002). 1: 500.000 Ölçekli Türkiye Jeoloji Haritası, Trabzon paftası, Jeolojik Araştırma Dairesi, MTA, Ankara.

25. Nageswara, R. K. (2020). Analysis of surface runoff potential in ungauged basin using basin parameters and SCS-CN method, Applied Water Science, 10, 47.

26. Özhan, S. (2004). Havza Amenajmanı. İ.Ü. Orman Fakültesi Havza Amenajmanı Anabilim Dalı, İ.Ü. Rektörlük Yayın No: 4510, Orman Fakültesi Yayın No: 481, İstanbul, 384 s.

27. Pophare, A. M., Balpande, U. S. (2014). Morphometric analysis of Suketi river basin, Himachal Himalaya, India, Journal of Earth System Science, 123 (7), 1501-1515.

28. Rai, P.K., Mishra, V. N., Mohan, K. (2017). A study of morphometric evaluation of the Son basin, India using geospatial approach, Remote Sensing Applications: Society and Environment, 7, 9-20.

29. Rai, P. K., Chandel, R. S., Mishra, V. N, Singh, P. (2018) Hydrological inferences through morphometric analysis of lower Kosi river basin of India for water resource management based on remote sensing data. Applied Water Science, 8, 15.

30. Reddy, G. P. O., Maji, A. K., Gajbhiye, K. S. (2004). Drainage morphometry and its influence on landform characteristics in a basaltic terrain, Central India - A remote sensing and GIS approach. International Journal of Applied Earth Observation and Geoinformation, 6, 1-16.

31. Rodriguez-Iturbe, I., Escobar, L. A. (1982). The dependence of drainage density on climate and geomorphology, Hydrological Sciences Journal, 27 (2), 129-137.

32. Schumm, S. A. (1956). Evolution of drainage systems and slopes in badlands at Perth Amboy, New Jersey, Geological Society of America Bulletin, 67, 597-646.

33. Singh, S., Singh, M. C. (1997). Morphometric analysis of Kanhar river basin. Natl Geogr J India, 43 (1), 31-43.

34. Singh, S. (1998). Geomorphology. Prayag Pustak Bhawan, Allahabad, 613 s.

35. Smith, K. G. (1950). Standards for Grading Textures of Erosional Topography. American Journal of Science, 248, 655-668.

36. Sreedevi, P. D., Subrahmanyam, K., Ahmed, S. (2004). The significance of morphometric analysis for obtaining groundwater potential zones in a structurally controlled terrain, Environmental Geology, 47, 412420.

37. Strahler, A. N. (1964). Quantative geomorphology of drainage basins and channel networks. In Handbook of applied hydrology Ed. Chow, V. T., McGraw Hill, New York, s. 439-476.

38. SYGM (T.C. Orman ve Su İşleri Bakanlığı, Su Yönetimi Genel Müdürlüğü) (2016). İklim Değişikliğinin Su Kaynaklarına Etkisi Projesi, Proje Nihai Raporu, 135 s.

39. Taha, M. M. N., Elbarbary, S. M., Naguib, D. M. El-Shamy, I. Z. (2017). Flash flood hazard zonation based on basin morphometry using remote sensing and GIS techniques: A case study of Wadi Qena basin, Eastern Desert, Egypt, Remote Sensing Applications: Society and Environment, 8, 157-167.

40. Waikar, M. L., Nilawar, A. P. (2014). Morphometric analysis of a drainage basin using Geographical Information System: A case study, International Journal of Multidisciplinary and Current Research, 2.

41. Yıldırım, Ü., Güler, C., Önol, B., Rode, M., Jomaa, S., (2021). Modelling of the Discharge Response to Climate Change under RCP8.5 Scenario in the Alata River Basin (Mersin, SE Turkey), Water, 13, 483. 